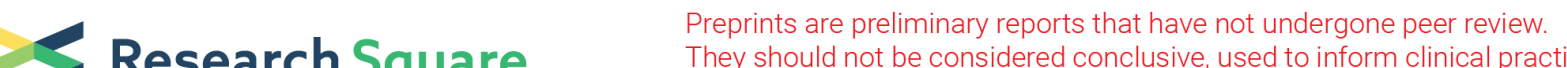 Research Square They should not be considered conclusive, used to inform clinical practice, or referenced by the media as validated information.
}

\section{Evaluating the Effect of Statins on Prognosis in Patients Undergoing Liver Transplantation for Hepatocellular Carcinoma}

Hae Lim Lee

Catholic University of Korea https://orcid.org/0000-0002-3242-8883

\section{Sung Won Lee}

Catholic University of Korea

Jeong Won Jang ( $\nabla$ garden@catholic.ac.kr)

Catholic University of Korea

Si Hyun Bae

Catholic University of Korea

Jong Young Choi

Catholic University of Korea

Nam Ik Han

Catholic University of Korea

\section{Seung Kew Yoon}

Catholic University of Korea

Ho Joong Choi

Catholic University of Korea

Gun Hyung $\mathrm{Na}$

Catholic University of Korea

\section{Young Kyoung You}

Catholic University of Korea

II Young Park

Catholic University of Korea

Dong Goo Kim

Catholic University of Korea

\section{Research Article}

Keywords: statin, hepatocellular carcinoma, liver transplantation, recurrence, mortality

Posted Date: February 16th, 2021

DOI: https://doi.org/10.21203/rs.3.rs-196683/v1 
License: (c) (i) This work is licensed under a Creative Commons Attribution 4.0 International License. Read Full License 


\section{Abstract}

Introduction

The anti-cancer effect of statins is drawing attention. However, it is unclear whether statin use reduces the risk of hepatocellular carcinoma (HCC) recurrence in patients who undergo liver transplantation (LT) for HCC.

Methods

Consecutive patients who underwent LT for HCC between 1995 and 2019 were enrolled. The effect of statins were compared between statin non-user and statin user groups. The primary endpoint was HCC recurrence. All-cause and HCC-related mortality were also evaluated. We also performed multivariablestratified and sensitivity analyses for HCC recurrence.

Results

A total of 430 patients was enrolled, among whom 323 (75.1\%) were statin non-users and $107(24.9 \%)$ were statin users. During a median of 64.9 months (IQR, 26.1-122.6) of follow-up, 79 patients (18.4\%) had HCC recurrence and 111 (25.8\%) died. Among those who died, 53 (47.7\%) were identified as HCCrelated mortalities. Statin use was associated with a significantly lower risk of HCC recurrence (adjusted $\mathrm{HR}=0.26,95 \% \mathrm{Cl}, 0.11-0.60 ; P=0.002)$ compared to that in statin non-users. Statin users also had significantly lower all-cause and HCC-related mortality than did statin non-users $(P<0.001 \& P=0.040$, respectively). There was a dose-dependent relationship between statin use and $\mathrm{HCC}$ recurrence. The anticancer effect of statins on HCC recurrence was consistently significant across multivariable-stratified and sensitivity analyses.

Conclusions

Statin use significantly reduced the risk of HCC recurrence and improved the survival of patients who underwent LT for HCC.

\section{Introduction}

Liver transplantation (LT) is a curative treatment for hepatocellular carcinoma (HCC) and is the only option in patients with deteriorated liver function. In HCC patients within the Milan criteria, the 5-year overall survival rate after $\mathrm{LT}$ is about $70 \%$, and the 5 -year $\mathrm{HCC}$ recurrence rate is about $10 \%$.[1,2] In recent years, to actively expand the selection criteria for LT, patients with tumors beyond the Milan criteria are frequently downstaged with locoregional therapies to fall within the Milan criteria. The incidence of HCC recurrence in these patients has been reported to be $15.5 \%$ at 5 years after LT.[1] As the demand for LT increases in HCC patients,[3] concurrent efforts have been made to improve the clinical outcomes of LT recipients. 
Statins, or 3-hydroxy-3-methylglutaryl coenzyme A (HMG-CoA) reductase inhibitors, are generally used in the treatment of dyslipidemia for preventing cardiovascular disease (CVD). Several observational studies have recently revealed that statins also exert anti-cancer effects in several cancers including HCC. $[4,5]$ Statin use was associated with a lower risk of HCC development in cohorts of chronic hepatitis B (CHB) patients and patients with liver cirrhosis (LC). $[6,7]$ In addition, statin use reduced mortality in LC patients with Child-Pugh class A or B and patients diagnosed with HCC.[6, 8] Statins directly affect the tumor microenvironment by regulating angiogenesis, inflammation, apoptosis, or growth and proliferation of cancer cells. [9] Many LT candidates for HCC have decreased liver function. Serum cholesterol levels are low in these patients, because the liver plays a major role in de novo synthesis of cholesterol.[10] However, serum cholesterol levels gradually recover approximately one month after LT,[11] and many LT recipients eventually require statin therapy given the increasing prevalence of dyslipidemia, diabetes, and hypertension, which are risk factors of CVD.[12, 13] Therefore, considering the anti-cancer effects of statins, we sought to investigate whether widely used statins independently affect recurrence in patients who undergo LT for HCC. We also analyzed the associations between statin use and all-cause and HCCrelated mortality.

\section{Methods}

\subsection{Patients}

This longitudinal cohort study enrolled a total of 458 patients 18 years of age or older who underwent LT for HCC between September 1995 and December 2019 at the liver unit of The Catholic University of Korea. The medical records of the patients were thoroughly reviewed. Patients were excluded if HCC recurred within 2 months of LT $(n=21)$, if follow-up was less than 3 months after $L T(n=25)$, or if patients started a statin within 1 month before $\mathrm{HCC}$ recurrence or after $\mathrm{HCC}$ recurrence $(n=5)$. There were patients with overlapping exclusion criteria. Ultimately, 430 patients were analyzed. In most patients, statin therapy was prescribed according to the treatment guidelines for dyslipidemia for primary or secondary prevention of CVD. The patients were followed until December 2019 or their last clinical visit. This study was approved by the Ethics Committees of The Catholic University of Korea in accordance with the 1975 Declaration of Helsinki (XC20RIDI0094). Patient consent was not necessary due to the retrospective nature of this study.

\subsection{Covariates and study outcomes}

The following clinical information was collected: treatment history of HCC before LT, laboratory results and tumor stage according to the Milan criteria at the time of LT, tumor pathology, type of LT, and mean trough concentration of calcineurin inhibitors ( $\mathrm{CNI}$ ) during the first month after LT. A higher mean trough concentration of CNI during the first month after LT but at no later time was significantly associated with HCC recurrence.[14] The prescription data for metformin and aspirin after $L T$ also were collected because these medications are suggested to have chemopreventive effects. The comorbid status of diabetes was 
investigated, including baseline and newly diagnosed diabetes after LT. The primary outcome was HCC recurrence. Secondary outcomes were all-cause and HCC-related mortality.

\subsection{Definitions}

The defined daily dose (DDD), according to the definition from the World Health Organization, was used to demonstrate the statin exposure. The cumulative DDD (cDDD) was calculated as the sum of the DDD during the follow-up period.[7] Although there is no evidence for the minimum period of statin use to exhibit anti-cancer effects, previous studies demonstrated the favorable effect of statins on clinical prognosis, including inhibition of HCC development in patients who used statins for at least 30 or 90 days. [7, 8] Therefore, we defined statin users as patients who had used statin for 30 or more consecutive cDDDs regardless of type. Additionally, we conducted sensitivity analyses, defining statin use as 90 or more consecutive cDDDs. We identified the starting date, duration of statin therapy, and daily dosage and types of statin. The statin types were largely divided into two groups, including lipophilic (atorvastatin, simvastatin, fluvastatin, and pitavastatin) and hydrophilic statin (rosuvastatin and pravastatin) groups. HCC-related mortality was defined as deterioration of liver function, other organ failure, or worsening performance status due to intra- or extrahepatic HCC recurrence or anti-tumor therapies that led to death. [15] The history of treatments indicated locoregional therapies for HCC performed before LT, such as radiofrequency ablation, percutaneous ethanol injection, surgical resection, transarterial chemoembolization, and others.

\subsection{Statistical analysis}

We divided the patients into statin non-user and statin user groups. The Chi-square test was used to compare categorical variables. The Wilcoxon signed-rank test was used to compare continuous variables. Kaplan-Meier's method was used for analysis of cumulative incidence of HCC recurrence, all-cause and HCC-related mortality and difference between the two groups was compared by the log-rank test. For analysis of $\mathrm{HCC}$ recurrence, death and loss to follow-up before HCC recurrence were considered competing events. Death from causes other than HCC and loss to follow-up were competing events for HCC-related mortality. The subdistribution hazard model by Fine and Gray was used to assess the association between statin use and patient outcome. The proportional hazards assumption was tested by the supremum test, log-log plot, and interaction term, which showed no significant violation. Subgroup analyses were conducted to evaluate the effect of statins on HCC recurrence in patient groups by: age (< 50 or $\geq 50$ ), sex (male or female), etiology (hepatitis b virus [HBV] or non-HBV), history of treatment before LT (no or yes), alpha-fetoprotein (AFP) (<100 or $\geq 100 \mathrm{ng} / \mathrm{mL}$ ), total cholesterol $(<200$ or $\geq 200$ $\mathrm{mg} / \mathrm{dL}$ ), Milan criteria (within or beyond), type of LT (living donor liver transplantation vs. deceased donor liver transplantation), diabetes (no or yes), and metformin use (no or yes).

We also conducted further analyses. The effect of cumulative statin dose over time on HCC recurrence was evaluated using Bonferroni's method for multiple comparisons. Furthermore, several sensitivity analyses were performed. First, we used landmark analysis to assess the significance of statin use in HCC recurrence compared to statin non-use at specific time points of 6,12 , and 24 months. In this 
method, patients who used statins during the exposure period up to the landmark date are considered statin users, and those who used statins after the landmark date are considered statin non-users; second, patients were enrolled since 2006, because the medical records were handwritten until December 2005 at our institutions and might be incomplete; third, patients who used statins for less than 90 cDDDs were excluded, thus the definition of a statin user was a patient who used statins for 90 or more consecutive CDDDs; fourth, patients who were followed up for less than 1 year and used statins for less than 90 cDDDs were excluded. A two-tailed $P$-value $<0.05$ was considered statistically significant. All analyses were performed using SAS software, version 9.4 (SAS Institute, Cary, NC).

\section{Results}

\subsection{Study population}

Of the 430 LT recipients included in this analysis, 323 (75.1\%) were assigned to the statin non-user group and 107 (24.9\%) were assigned to the statin user group. A comparison of clinical characteristics between the two groups is shown in Table 1. There were no significant differences between the statin non-user and statin user groups with regard to AFP level, tumor stage according to the Milan criteria, and tumor pathology, which are associated with HCC recurrence after LT. The proportion of patients with diabetes and that of those with aspirin or metformin use were significantly higher in the statin user group than in the statin non-user group (all $P$ values were $<0.001$ ). However, the proportion of patients newly diagnosed with diabetes after LT was not different between the two groups $(P=0.246)$. A median period between the date of $L T$ and starting a statin was 33.3 months (interquartile range [IQR], 7.8-59.5). The median cumulative dose of statin in the statin user group was 730 cDDDs (IQR, 420.5-1541.5). 
Table 1

Study population

\begin{tabular}{|c|c|c|c|}
\hline & $\begin{array}{l}\text { Post-LT statin non- } \\
\text { user } \\
(\mathrm{N}=323,75.1 \%)\end{array}$ & $\begin{array}{l}\text { Post-LT statin } \\
\text { user } \\
(\mathrm{N}=107,24.9 \%)\end{array}$ & $P$ \\
\hline Sex, male (\%) & $271(83.9)$ & $82(76.6)$ & 0.089 \\
\hline Age, mean (SD) & $53.3 \pm 8.0$ & $55.1 \pm 7.5$ & 0.036 \\
\hline HCC etiology & & & $\begin{array}{l}< \\
0.001\end{array}$ \\
\hline HBV & $279(86.4)$ & $82(76.6)$ & \\
\hline $\mathrm{HCV}$ & $24(7.4)$ & $5(4.7)$ & \\
\hline Non-viral & $20(6.2)$ & $20(18.7)$ & \\
\hline Milan, within criteria & $262(81.1)$ & $94(87.9)$ & 0.280 \\
\hline History of treatment before $\mathrm{LT}^{\dagger}$ & $237(73.4)$ & $81(75.7)$ & 0.635 \\
\hline Pre-LT AFP, median (IQR) & $11.4(4.2-77.5)$ & $10.9(3.8-37.6)$ & 0.260 \\
\hline Pre-LT AFP ( $\geq 100$ ng/mL) & $73(22.6)$ & $16(15.0)$ & 0.232 \\
\hline Pre-LT total cholesterol, mean (SD) & $124.2 \pm 42.0$ & $123.8 \pm 47.3$ & 0.883 \\
\hline $\begin{array}{l}\text { Pre-LT total cholesterol ( } \geq 200 \mathrm{mg} / \mathrm{dL}), \mathrm{N} \\
(\%)\end{array}$ & $14(4.3)$ & $4(3.7)$ & 0.803 \\
\hline \multicolumn{4}{|l|}{ Tumor pathology } \\
\hline Total necrosis & $76(23.5)$ & $22(20.6)$ & 0.621 \\
\hline Differentiation (E-S G 『-邓) & $101(31.3)$ & $22(20.6)$ & 0.048 \\
\hline Microvascular invasion & $78(24.1)$ & $17(15.9)$ & 0.159 \\
\hline LDLT & $298(92.3)$ & $97(90.7)$ & 0.599 \\
\hline
\end{tabular}

Data are expressed as the number (\%) for categorical variables, and mean \pm SD or median (range) for continuous variables.

${ }^{\dagger}$ The history of treatments indicated locoregional therapies for HCC performed before LT, such as radiofrequency ablation, percutaneous ethanol injection, surgical resection, transarterial chemoembolization, and others.

${ }^{\ddagger}$ Mean trough concentration of CNI during the first month after LT was measured.

Abbreviations: AFP, alpha-fetoprotein; CNI, calcineurin inhibitor; CSA, cyclosporine; E-S G, Edmondson-Steiner grade; HBV, hepatitis B virus; $\mathrm{HCC}$, hepatocellular carcinoma; $\mathrm{HCV}$, hepatitis $\mathrm{C}$ virus; IQR, interquartile range; LDLT, living donor liver transplantation; LT, liver transplantation; SD, standard deviation; Tac, tacrolimus. 


\begin{tabular}{|c|c|c|c|}
\hline & $\begin{array}{l}\text { Post-LT statin non- } \\
\text { user } \\
(\mathrm{N}=323,75.1 \%)\end{array}$ & $\begin{array}{l}\text { Post-LT statin } \\
\text { user } \\
(\mathrm{N}=107,24.9 \%)\end{array}$ & $P$ \\
\hline Use of aspirin after LT & $11(3.4)$ & $14(13.1)$ & $<_{0.001}$ \\
\hline Use of metformin after LT & $50(15.5)$ & $37(34.6)$ & $<.001$ \\
\hline Pre- and post-LT diabetes & $107(33.1)$ & $64(59.8)$ & $\begin{array}{l}< \\
0.001\end{array}$ \\
\hline Post-LT diabetes & $17(5.3)$ & $9(8.4)$ & 0.246 \\
\hline Statin type (hydrophilic/lipophilic) & & $60 / 47(56.1 / 43.9$ & \\
\hline $\begin{array}{l}\text { Mean trough concentration of } \mathrm{CNI}^{\ddagger} \\
(\mathrm{Tac}>10 \mathrm{ng} / \mathrm{mL}, \mathrm{CSA}>250 \mathrm{ng} / \mathrm{mL}), \mathrm{N}(\%)\end{array}$ & $25(7.7)$ & $8(7.5)$ & 0.139 \\
\hline \multicolumn{4}{|c|}{$\begin{array}{l}\text { Data are expressed as the number (\%) for categorical variables, and mean } \pm \text { SD or median (range) for } \\
\text { continuous variables. }\end{array}$} \\
\hline \multicolumn{4}{|c|}{$\begin{array}{l}\text { †The history of treatments indicated locoregional therapies for HCC performed before LT, such as } \\
\text { radiofrequency ablation, percutaneous ethanol injection, surgical resection, transarterial } \\
\text { chemoembolization, and others. }\end{array}$} \\
\hline \multicolumn{4}{|c|}{${ }^{\ddagger}$ Mean trough concentration of CNI during the first month after LT was measured. } \\
\hline
\end{tabular}

\subsection{Cumulative incidence of HCC recurrence}

During a median follow-up of 64.9 months (IQR, 26.1-122.6), HCC recurred in 79 patients (18.4\%), including $72(22.3 \%)$ in the statin non-user group and 7 (6.5\%) in the statin user group. Of those, 61 (77.2\%) patients had HCC recurrence that initially presented at extrahepatic site regardless of the presence of intrahepatic tumors. Sixty-three patients $(79.7 \%)$ had recurrence within 2 years of LT. The cumulative incidence of $\mathrm{HCC}$ recurrence at 2 and 5 years was $18.9 \%$ and $22.3 \%$ in the statin non-user group, and $3.8 \%$ and $5.7 \%$ in the statin user group, respectively $(P<0.001)$ (Fig. 1. a).

\subsection{Cumulative incidence of all-cause and HCC-related mortality}

Overall, 111 patients (25.8\%) died including $98(30.3 \%)$ in the statin non-user group and $13(12.1 \%)$ in the statin user group. Of those, 53 patients $(47.7 \%)$ were identified as HCC-related mortalities. The 2-year and 5 -year cumulative incidences of all-cause mortality were $18.4 \%$ and $29.5 \%$, respectively, in the statin non- 
user group, and $2.7 \%$ and $6.4 \%$ in the statin user group $(P<0.001)$ (Fig. 1. b). The cumulative incidence of HCC-related mortality was significantly higher in the statin non-user group than in the statin user group.

The 2-year and 5-year cumulative incidences were $11.0 \%$ and $14.5 \%$ in the statin non-user group and $1.8 \%$ and $3.6 \%$ in the statin user group, respectively $(P=0.003)$ (Fig. 1. C).

\subsection{Prognostic factors for HCC recurrence}

In univariable analysis, there was a significant association between statin use and HCC recurrence (hazard ratio [HR], 0.25; 95\% confidence interval [Cl], 0.12-0.54; $P<0.001$ ). The independent predictors of HCC recurrence were elevated AFP level, history of treatment before LT, tumor stage beyond the Milan criteria, and metformin non-users. In multivariable analysis, the following remained independent factors for HCC recurrence: elevated AFP level (HR, 2.15; 95\% Cl, 1.26-3.67; $P=0.005)$, history of treatment before LT (HR, 2.71; 95\% Cl, 1.49-4.92; $P=0.001)$, tumor stage beyond the Milan criteria (HR, $4.47 ; 95 \%$ $\mathrm{Cl}, 2.69-7.42 ; P<0.001)$, and metformin (HR, 0.36; 95\% Cl, 0.14-0.88; $P=0.026)$ and statin use (HR, 0.26; $95 \% \mathrm{Cl}, 0.11-0.60 ; P=0.002$ ) (Table 2). The risk of HCC recurrence decreased with increasing cumulative statin doses, with the lowest risk above $730 \mathrm{cDDDs}(P$ for trend $=0.001)$ (Table 3$)$. 
Table 2

Cox regression analysis for HCC recurrence

\begin{tabular}{|c|c|c|c|c|}
\hline & \multicolumn{2}{|l|}{ Univariate } & \multicolumn{2}{|l|}{ Multivariate } \\
\hline & $\mathrm{HR}(95 \% \mathrm{Cl})$ & $P$ & $\mathrm{HR}(95 \% \mathrm{Cl})$ & $P$ \\
\hline Sex (female vs. male) & $\begin{array}{l}0.88(0.49- \\
1.59)\end{array}$ & 0.670 & $\begin{array}{l}1.13(0.54- \\
2.35)\end{array}$ & 0.753 \\
\hline Age $(\geq 50$ vs. < 50) & $\begin{array}{l}0.63(0.40- \\
1.00)\end{array}$ & 0.050 & $\begin{array}{l}0.60(0.36- \\
1.01)\end{array}$ & 0.052 \\
\hline $\begin{array}{l}\text { Total cholesterol ( } \geq 200 \text { vs. }<200 \\
\mathrm{mg} / \mathrm{dL} \text { ) }\end{array}$ & $\begin{array}{l}1.61(0.65- \\
4.01)\end{array}$ & 0.303 & $\begin{array}{l}1.56(0.65- \\
3.75)\end{array}$ & 0.322 \\
\hline AFP $(\geq 100$ vs. $<100$ ng/mL) & $\begin{array}{l}3.16(2.01- \\
4.98)\end{array}$ & $<001$ & $\begin{array}{l}2.15(1.26- \\
3.67)\end{array}$ & 0.005 \\
\hline $\begin{array}{l}\text { History of treatment before } \mathrm{LT}^{\dagger} \text { (yes vs. } \\
\text { no) }\end{array}$ & $\begin{array}{l}2.15(1.16- \\
3.99)\end{array}$ & 0.015 & $\begin{array}{l}2.71(1.49- \\
4.92)\end{array}$ & 0.001 \\
\hline Milan (beyond vs. within) & $\begin{array}{l}5.89(3.78- \\
9.19)\end{array}$ & $<0.001$ & $\begin{array}{l}4.47(2.69- \\
7.42)\end{array}$ & $<0.001$ \\
\hline $\begin{array}{l}\text { Mean trough concentration of } \mathrm{CNI}^{\ddagger} \\
\text { (high vs. normal) }\end{array}$ & $\begin{array}{l}0.91(0.38- \\
2.19)\end{array}$ & 0.826 & $\begin{array}{l}0.72(0.29- \\
1.75)\end{array}$ & 0.462 \\
\hline $\begin{array}{l}\text { Diabetes before and/or after LT (yes vs. } \\
\text { no) }\end{array}$ & $\begin{array}{l}0.82(0.52- \\
1.29)\end{array}$ & 0.388 & $\begin{array}{l}1.20(0.68- \\
2.13)\end{array}$ & 0.532 \\
\hline Use of aspirin after LT (yes vs. no) & - & - & - & - \\
\hline Use of metformin after LT (yes vs. no) & $\begin{array}{l}0.30(0.13- \\
0.68)\end{array}$ & 0.004 & $\begin{array}{l}0.36(0.14- \\
0.88)\end{array}$ & 0.026 \\
\hline Use of statin after LT (yes vs. no) & $\begin{array}{l}0.25(0.12- \\
0.54)\end{array}$ & $<0.001$ & $\begin{array}{l}0.26(0.11- \\
0.60)\end{array}$ & 0.002 \\
\hline \multicolumn{5}{|c|}{$\begin{array}{l}{ }^{\dagger} \text { The history of treatments indicated locoregional therapies for HCC performed before LT, such as } \\
\text { radiofrequency ablation, percutaneous ethanol injection, surgical resection, transarterial } \\
\text { chemoembolization, and others. }\end{array}$} \\
\hline \multicolumn{5}{|c|}{$\begin{array}{l}\text { FThe high mean trough concentration of CNI during the first month after LT was defined when the } \\
\text { mean trough concentration of tacrolimus was above } 10 \mathrm{ng} / \mathrm{mL} \text { or that of cyclosporine was above } 250 \\
\mathrm{ng} / \mathrm{mL} \text {. }\end{array}$} \\
\hline
\end{tabular}


Table 3

Dose-dependent relationship between statin use and $\mathrm{HCC}$ recurrence

\begin{tabular}{|c|c|c|c|c|}
\hline cDDDs & Event No./Total No. (\%) & Adjusted HR $(95 \% \mathrm{Cl})^{\dagger}$ & $P^{\sharp}$ & $P$ value for trend \\
\hline No statin & 72/323 (22.3) & Reference & & 0.001 \\
\hline$<365$ & $2 / 22(9.1)$ & $0.45(0.08-2.41)$ & 0.761 & \\
\hline $365-730$ & $4 / 32(12.5)$ & $0.44(0.11-1.72)$ & 0.450 & \\
\hline$>730$ & $1 / 53(1.9)$ & $0.08(0.01-0.89)$ & 0.038 & \\
\hline
\end{tabular}

${ }^{\dagger}$ Cox regression analysis adjusting for sex, age, total cholesterol ( $\geq 200 \mathrm{vs} .<200 \mathrm{mg} / \mathrm{dL}$ ), AFP $(\geq 100$ vs. $<100 \mathrm{ng} / \mathrm{mL}$ ), history of treatment before LT (yes vs. no), Milan criteria (beyond vs. within), mean trough concentration of CNI (high vs. normal), diabetes before and/or after LT (yes vs. no), use of metformin after LT (yes vs. no).

${ }^{\ddagger}$ Corrected using Bonferroni's method due to multiple testing (number of tests: 3 )

Abbreviations: AFP, alpha-fetoprotein; $\mathrm{CDDD}$, cumulative daily defined dose; $\mathrm{Cl}$, confidence interval; $\mathrm{CNI}$, calcineurin inhibitor; HCC, hepatocellular carcinoma; HR, hazard ratio; LT, liver transplantation.

\subsection{Prognostic factors for all-cause and HCC-related mortality}

Based on multivariable analysis, the following parameters were independent factors of all-cause mortality: elevated AFP level $(\mathrm{HR}, 1.84 ; 95 \% \mathrm{Cl}, 1.18-2.86 ; P=0.007)$; history of treatment before LT (HR, $3.21 ; 95 \% \mathrm{Cl}, 1.81-5.68 ; P<0.001)$; tumor stage beyond the Milan criteria (HR, 2.45; $95 \% \mathrm{Cl}, 1.59-3.79 ; P$ $<0.001)$; presence of diabetes (HR, 1.79; $95 \% \mathrm{Cl}, 1.16-2.75 ; P=0.008)$; metformin use (HR, $0.22 ; 95 \% \mathrm{Cl}$, 0.10-0.48; $P<0.001)$; and statin use (HR, $0.26 ; 95 \% \mathrm{Cl}, 0.14-0.49 ; P<0.001)$ (Table 4). In multivariable analysis for HCC-related mortality, the following remained independent predictive factors of all-cause mortality: elevated AFP level (HR, 2.07; 95\% Cl, 1.06-4.06; $P=0.033)$; history of treatment before LT (HR, $3.38 ; 95 \% \mathrm{Cl}, 1.46-7.83 ; P=0.005)$; tumor stage beyond the Milan criteria (HR, 3.10; $95 \% \mathrm{Cl}, 1.56-6.15 ; P$ $=0.001)$; metformin use $(\mathrm{HR}, 0.07 ; 95 \% \mathrm{Cl}, 0.01-0.53 ; P=0.010)$; and statin use $(\mathrm{HR}, 0.37 ; 95 \% \mathrm{Cl}, 0.14-$ $0.95 ; P=0.040$ ). 
Table 4

Cox regression of all-cause and HCC-related mortality

\begin{tabular}{|c|c|c|c|c|}
\hline & \multicolumn{2}{|c|}{ All-cause mortality } & \multicolumn{2}{|c|}{ HCC-related mortality } \\
\hline & $\mathrm{HR}(95 \% \mathrm{Cl})$ & $P$ & $\mathrm{HR}(95 \% \mathrm{Cl})$ & $P$ \\
\hline Sex (female vs. male) & $\begin{array}{l}0.79(0.46- \\
1.35)\end{array}$ & 0.385 & $\begin{array}{l}1.00(0.44- \\
2.28)\end{array}$ & 0.993 \\
\hline Age $(\geq 50$ vs. $<50)$ & $\begin{array}{l}1.29(0.83- \\
2.02)\end{array}$ & 0.263 & $\begin{array}{l}0.81(0.43- \\
1.55)\end{array}$ & 0.528 \\
\hline Total cholesterol ( $\geq 200$ vs. $<200$ mg/dL) & $\begin{array}{l}0.87(0.32- \\
2.41)\end{array}$ & 0.795 & $\begin{array}{l}0.90(0.29- \\
2.81)\end{array}$ & 0.852 \\
\hline AFP $(\geq 100$ vs. $<100 \mathrm{ng} / \mathrm{mL})$ & $\begin{array}{l}1.84(1.18- \\
2.86)\end{array}$ & 0.007 & $\begin{array}{l}2.07(1.06- \\
4.06)\end{array}$ & 0.033 \\
\hline $\begin{array}{l}\text { History of treatment before } \mathrm{LT}^{\dagger} \text { (yes vs. } \\
\text { no) }\end{array}$ & $\begin{array}{l}3.21(1.81- \\
5.68)\end{array}$ & $<.001$ & $\begin{array}{l}3.38(1.46- \\
7.83)\end{array}$ & 0.005 \\
\hline Milan (beyond vs. within) & $\begin{array}{l}2.45(1.59- \\
3.79)\end{array}$ & $<.001$ & $\begin{array}{l}3.10(1.56- \\
6.15)\end{array}$ & 0.001 \\
\hline $\begin{array}{l}\text { Mean trough concentration of } \mathrm{CNI}^{\ddagger} \\
\text { (high vs. normal) }\end{array}$ & $\begin{array}{l}1.03(0.54- \\
1.97)\end{array}$ & 0.920 & $\begin{array}{l}0.72(0.23- \\
2.23)\end{array}$ & 0.564 \\
\hline $\begin{array}{l}\text { Diabetes before and/or after LT (yes vs. } \\
\text { no) }\end{array}$ & $\begin{array}{l}1.79(1.16- \\
2.75)\end{array}$ & 0.008 & $\begin{array}{l}1.45(0.78- \\
2.71)\end{array}$ & 0.238 \\
\hline Use of aspirin after LT (yes vs. no) & $\begin{array}{l}1.07(0.41- \\
2.77)\end{array}$ & 0.889 & $\begin{array}{l}0.44(0.06- \\
3.21)\end{array}$ & 0.418 \\
\hline Use of metformin after LT (yes vs. no) & $\begin{array}{l}0.22(0.10- \\
0.48)\end{array}$ & $<.001$ & $\begin{array}{l}0.07(0.01- \\
0.53)\end{array}$ & 0.010 \\
\hline Use of statin after LT (yes vs. no) & $\begin{array}{l}0.26(0.14- \\
0.49)\end{array}$ & $<.001$ & $\begin{array}{l}0.37(0.14- \\
0.95)\end{array}$ & 0.040 \\
\hline \multicolumn{5}{|c|}{$\begin{array}{l}\text { †The history of treatments indicated locoregional therapies for HCC performed before LT, such as } \\
\text { radiofrequency ablation, percutaneous ethanol injection, surgical resection, transarterial } \\
\text { chemoembolization, and others. }\end{array}$} \\
\hline \multicolumn{5}{|c|}{$\begin{array}{l}\text { FThe high mean trough concentration of CNI during the first month after LT was defined when the } \\
\text { mean trough concentration of tacrolimus was above } 10 \mathrm{ng} / \mathrm{mL} \text { or that of cyclosporine was above } 250 \\
\mathrm{ng} / \mathrm{mL} \text {. }\end{array}$} \\
\hline
\end{tabular}

\subsection{Multivariable-stratified analyses}

Multivariable-stratified analyses verified the effect of statins on HCC recurrence in almost all subgroups, especially in male patients $(\mathrm{HR}, 0.18 ; 95 \% \mathrm{Cl}, 0.07-0.49 ; P=0.001)$ and patients without diabetes $(\mathrm{HR}$, 
$0.18 ; 95 \% \mathrm{Cl}, 0.04-0.74 ; P=0.017)$. Although statistical insignificance was noted in female patients $(P=$ $0.362)$ and patients with non-HBV etiologies $(P=0.125)$, total cholesterol $(\geq 200)(P>0.999)$, and metformin use $(P=0.557)$, the effect of statin was homogeneous between subgroups (all interaction $P$ values were $>0.100)$ (Fig. 2).

\subsection{Sensitivity analyses}

In landmark analysis, statin use was independently associated with HCC recurrence at 6 and 12 months (adjusted HR, 0.15; 95\% $\mathrm{Cl} 0.05-0.52 ; P=0.003$ and adjusted $\mathrm{HR}, 0.20 ; 95 \% \mathrm{Cl} 0.05-0.85 ; P=0.029$, respectively). Statin use tended to reduce $\mathrm{HCC}$ recurrence at 24 months without statistical significance (adjusted HR, 0.15; 95\% Cl 0.02-1.15; $P=0.068$ ) (Table S1). In further analyses, statin use remained an independent factor across all the following scenarios (Table S2-4): 1) patients enrolled since 2006 (adjusted HR, 0.30; 95\% $\mathrm{Cl} 0.12-0.73 ; P=0.008) ; 2$ ) statin users defined as patients who used statins for 90 or more cDDDs (adjusted HR, $0.27 ; 95 \% \mathrm{Cl} 0.12-0.62 ; P=0.002$ ); 3 ) a follow-up period of at least 1 year and statin users defined as patients who used statins for 90 or more CDDDs (adjusted HR, $0.37 ; 95 \%$ Cl 0.14-0.97; $P=0.044)$.

\section{Discussion}

This study demonstrates that statin use substantially reduced the risk of HCC recurrence in patients who underwent LT for HCC. This protective effect of statins on LT recipients was consistently significant across subgroups and sensitivity analyses. The benefit of statins was dose-dependent, with the lowest risk of HCC recurrence when the medications were used for more than two years (>730 CDDDs). This study also demonstrated that statin use significantly reduced all-cause and HCC-related mortality in LT recipients. Although clinicians often hesitate to use statins because of their potential hepatotoxicity, our study provides compelling evidence that HCC patients who undergo LT would benefit from statin use to improve their overall clinical outcomes.

HCC mostly occurs in chronically inflamed liver, and LT is a way to eliminate HCC while treating chronic liver disease. However, HCC often recurs, even in LT recipients. HCC recurrence is caused by occult metastasis remaining at the time of $\mathrm{LT}$ or, rarely, by circulating cancer cells that are released intraoperatively.[16] Thus, a significant proportion of HCC recurrence occurs at extrahepatic sites, such as the lungs and bones. $[17,18]$ Previous studies investigated the use of statins as anti-cancer agents. Statin inhibits HMG-CoA reductase, the rate-limiting enzyme, at the early step in the mevalonate cascade. Therefore, it exerts pleiotropic, anti-cancer effects by subsequently inhibiting the synthesis of several molecules in this pathway. Inhibition of the prenylation of G-proteins, especially geranylgeranyl pyrophosphate prenylation (geranylgeranylation) of Rho proteins, is considered the key to the anti-cancer effects of statin.[9] Theoretically, statins are expected to actively affect cancer cells because the expression of HMG-CoA reductase and the demand for isoprenoids intermediates in the mevalonate pathway are increased in cancer cells.[19] 
To evaluate the association between statin use and $\mathrm{HCC}$ recurrence, this study incorporated tumor-related factors of pre-LT AFP level, tumor stage according to the Milan criteria, and pre-LT treatment history as covariates in analyses of $\mathrm{HCC}$ recurrence because these have the greatest influence on HCC recurrence after LT.[20] We identified the anti-cancer effect of statin even after adjusting for these tumor-related factors. The effect of statins was most pronounced in patients who used them for more than 2 years (730 cDDDs). This finding is consistent with previous results describing a cumulative effect of statins. Prior works found that CHB patients benefited most from statin use for $>3$ years, and LC patients experienced an $8 \%$ reduced risk of mortality with each year of statin exposure.[6, 7] Considering this timedependent effect, we expect that early use of statins, if clinically indicated, may be beneficial against HCC recurrence.

In this study, metformin, aspirin, and diabetes, which are known to affect HCC development in patients with liver disease, were included as covariates in the analyses of clinical outcomes in LT recipients. Although metformin use was one of the independent factors related to reduced risk of HCC recurrence, its significance was not maintained through sensitivity analyses. Previous cohort studies, as well as experiments in vitro or in vivo, have demonstrated that metformin affects carcinogenesis, either directly or by suppressing hyperinsulinemia.[21,22] However, there is little evidence regarding the effect of metformin on the clinical outcomes of LT recipients. Importantly, the anti-cancer effect of metformin must be interpreted with caution because it is generally prescribed only for patients with diabetes. In this study, diabetes diagnosed before or after LT did not affect HCC recurrence or HCC-related mortality despite being a well-known predictor of HCC development.[23] Rather, the presence of diabetes only remained an independent predictor of all-cause mortality.

As mentioned earlier, the prevalence of metabolic diseases increased over time in LT recipients. In this study, approximately one-quarter of the enrolled patients were eventually treated with statins, and most met the treatment criteria for statins to prevent CVD. We investigated the prevalence of diabetes before and after LT but did not analyze dyslipidemia, hypertension, or obesity. These factors are components of metabolic syndrome and risk factors for HCC development in the general population.[24] Although metabolic diseases not measured in this study may have confounded the analysis of HCC recurrence or survival, there is lack of evidence regarding the impact of metabolic diseases on HCC recurrence in LT recipients. Of note, previous studies that included LT patients for any indication demonstrated inconsistent results regarding the impact of diabetes on survival and found that hypertension and dyslipidemia were not significant predictors of long-term survival.[12, 25] Furthermore, diabetes has not been shown to be associated with development of de novo cancer.[12, 25] Further studies are needed to elucidate the impact of metabolic diseases on clinical outcomes in patients who undergo LT for HCC.

This study had several limitations, mainly related to its retrospective nature. Each patient was started on a statin at a different time point in disease. This inconsistency could have caused immortal time bias in analyses of primary outcome. To overcome this limitation, we performed a dose-dependent analysis to evaluate the association between statin use and HCC recurrence. Furthermore, sensitivity analyses including that with the landmark method frequently used to avoid this type of bias showed consistent 
results across the cohort. In this study, we attempted to identify a specific patient group in which statins were the most effective through multivariable-stratified analyses. However, this analysis was limited by an insufficient sample size despite the large total sample size of HCC patients who underwent LT.

In conclusion, the use of statins in HCC patients who undergo LT significantly reduces HCC recurrence and improves survival. The results from this study provide insights into the early and active use of statins to improve overall liver-related events as well as prevent CVD in LT recipients.

\section{Abbreviations}

AFP, alpha-fetoprotein; CHB, chronic hepatitis $\mathrm{B}$; Cl, confidence interval; CNI, calcineurin inhibitors; CVD, cardiovascular disease; DDD, defined daily dose; HBV, hepatitis b virus; $\mathrm{HCC}$, hepatocellular carcinoma; HMG-CoA, 3-hydroxy-3-methylglutaryl coenzyme a; IQR, interquartile range; HR, hazard ratio; LC, liver cirrhosis; LT, liver transplantation

\section{Declarations}

Funding : Not applicable

Conflicts of interest: The authors of this manuscript have no conflicts of interest to disclose.

Ethics approval : This study was approved by the Ethics Committees of The Catholic University of Korea in accordance with the 1975 Declaration of Helsinki (XC20RIDI0094). Patient consent was not necessary due to the retrospective nature of this study.

Availability of data : The data that support the findings of this study are available from the corresponding author upon reasonable request.

\section{Authors' contributions}

Guarantor of the article: Jeong Won Jang

Specific author contributions: Study concept and design: Jeong Won Jang and Hae Lim Lee; collecting and interpreting data: Jeong Won Jang and Hae Lim Lee; Contributed reagents/materials/analysis tools: Hae Lim Lee, Sung Won Lee, Jeong Won Jang, Si Hyun Bae, Jong Young Choi, Nam Ik Han, Seung Kew Yoon, Ho Joong Choi, Gun Hyung Na, Young Kyoung You, II Young Park, Dong Goo Kim; Wrote the paper: Jeong Won Jang and Hae Lim Lee. All authors have approved this final version of the manuscript.

\section{References}

1. Kardashian A, Florman SS, Haydel B, Ruiz RM, Klintmalm GB, Lee DD, et al. Liver Transplantation Outcomes in a U.S. Multicenter Cohort of 789 Patients with Hepatocellular Carcinoma Presenting Beyond Milan Criteria. Hepatology 2020. doi: 10.1002/hep.31210 
2. Clavien P-A, Lesurtel M, Bossuyt PMM, Gores GJ, Langer B, Perrier A. Recommendations for liver transplantation for hepatocellular carcinoma: an international consensus conference report. The Lancet Oncology 2012;13:e11-e22

3. Lee HW, Suh KS. Liver transplantation for advanced hepatocellular carcinoma. Clin Mol Hepatol 2016;22:309-318

4. Tran KT, McMenamin UC, Coleman HG, Cardwell CR, Murchie P, Iversen L, et al. Statin use and risk of liver cancer: Evidence from two population-based studies. Int J Cancer 2019;146:1250-1260

5. Fatehi Hassanabad A. Current perspectives on statins as potential anti-cancer therapeutics: clinical outcomes and underlying molecular mechanisms. Transl Lung Cancer Res 2019;8:692-699

6. Kaplan DE, Serper MA, Mehta R, Fox R, John B, Aytaman A, et al. Effects of Hypercholesterolemia and Statin Exposure on Survival in a Large National Cohort of Patients With Cirrhosis. Gastroenterology 2019;156:1693-1706 e1612

7. Goh MJ, Sinn DH, Kim S, Woo SY, Cho H, Kang W, et al. Statin Use and the Risk of Hepatocellular Carcinoma in Patients With Chronic Hepatitis B. Hepatology 2020;71:2023-2032

8. Thrift AP, Natarajan Y, Liu Y, El-Serag HB. Statin Use After Diagnosis of Hepatocellular Carcinoma Is Associated With Decreased Mortality. Clin Gastroenterol Hepatol 2019;17:2117-2125 e2113

9. Demierre MF, Higgins PD, Gruber SB, Hawk E, Lippman SM. Statins and cancer prevention. Nat Rev Cancer 2005;5:930-942

10. Habib A, Mihas AA, Abou-Assi SG, Williams LM, Gavis E, Pandak WM, et al. High-density lipoprotein cholesterol as an indicator of liver function and prognosis in noncholestatic cirrhotics. Clin Gastroenterol Hepatol 2005;3:286-291

11. Wolf JH, Holmes MV, Fouraschen S, Keating BJ, Baker T, Emond J, et al. Serum lipid expression correlates with function and regeneration following living donor liver transplantation. Liver Transpl 2016;22:103-110

12. Parekh J, Corley DA, Feng S. Diabetes, hypertension and hyperlipidemia: prevalence over time and impact on long-term survival after liver transplantation. Am J Transplant 2012;12:2181-2187

13. Patel SS, Rodriguez VA, Siddiqui MB, Faridnia M, Lin FP, Chandrakumaran A, et al. The Impact of Coronary Artery Disease and Statins on Survival After Liver Transplantation. Liver Transpl 2019;25:1514-1523

14. Rodriguez-Peralvarez M, Tsochatzis E, Naveas MC, Pieri G, Garcia-Caparros C, O'Beirne J, et al. Reduced exposure to calcineurin inhibitors early after liver transplantation prevents recurrence of hepatocellular carcinoma. J Hepatol 2013;59:1193-1199

15. Cucchetti A, Serenari M, Sposito C, Di Sandro S, Mosconi C, Vicentin I, et al. Including mRECIST in the Metroticket 2.0 criteria improves prediction of hepatocellular carcinoma-related death after liver transplant. J Hepatol 2020;76:342-348

16. Toso C, Mentha G, Majno P. Liver transplantation for hepatocellular carcinoma: five steps to prevent recurrence. Am J Transplant 2011;11:2031-2035 
17. Sapisochin G, Goldaracena N, Astete S, Laurence JM, Davidson D, Rafael E, et al. Benefit of Treating Hepatocellular Carcinoma Recurrence after Liver Transplantation and Analysis of Prognostic Factors for Survival in a Large Euro-American Series. Ann Surg Oncol 2015;22:2286-2294

18. Bodzin AS, Lunsford KE, Markovic D, Harlander-Locke MP, Busuttil RW, Agopian VG. Predicting Mortality in Patients Developing Recurrent Hepatocellular Carcinoma After Liver Transplantation: Impact of Treatment Modality and Recurrence Characteristics. Ann Surg 2017;266:118-125

19. Hentosh P, Yuh SH, Elson CE, Peffley DM. Sterol-independent regulation of 3-hydroxy-3-methylglutaryl coenzyme A reductase in tumor cells. Mol Carcinog 2001;32:154-166

20. Sapisochin G, Bruix J. Liver transplantation for hepatocellular carcinoma: outcomes and novel surgical approaches. Nat Rev Gastroenterol Hepatol 2017;14:203-217

21. Chen HP, Shieh JJ, Chang CC, Chen TT, Lin JT, Wu MS, et al. Metformin decreases hepatocellular carcinoma risk in a dose-dependent manner: population-based and in vitro studies. Gut 2013;62:606615

22. Yu H, Zhong X, Gao P, Shi J, Wu Z, Guo Z, et al. The Potential Effect of Metformin on Cancer: An Umbrella Review. Front Endocrinol (Lausanne) 2019;10:617

23. Davila JA, Morgan RO, Shaib Y, McGlynn KA, El-Serag HB. Diabetes increases the risk of hepatocellular carcinoma in the United States: a population based case control study. Gut 2005;54:533-539

24. Simon TG, King LY, Chong DQ, Nguyen LH, Ma Y, VoPham T, et al. Diabetes, metabolic comorbidities, and risk of hepatocellular carcinoma: Results from two prospective cohort studies. Hepatology 2018;67:1797-1806

25. Aravinthan AD, Fateen W, Doyle AC, Venkatachalapathy SV, Issachar A, Galvin Z, et al. The Impact of Preexisting and Post-transplant Diabetes Mellitus on Outcomes Following Liver Transplantation. Transplantation 2019;103:2523-2530

\section{Figures}


Figure 1

b.

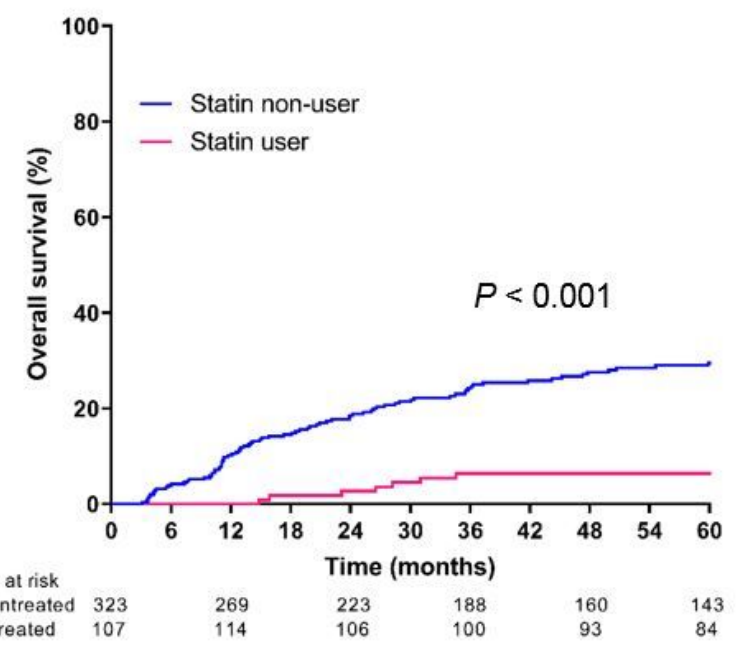

a.

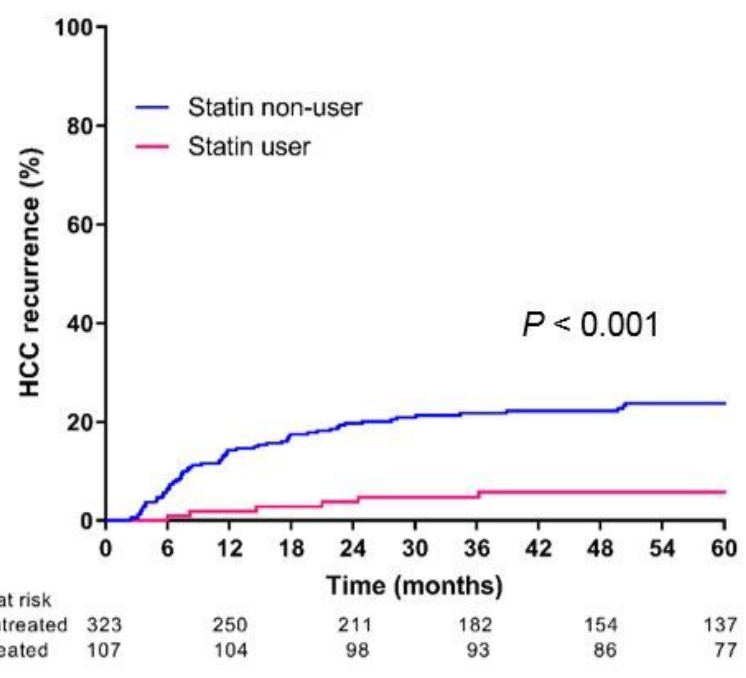

\section{Figure 1}

c.

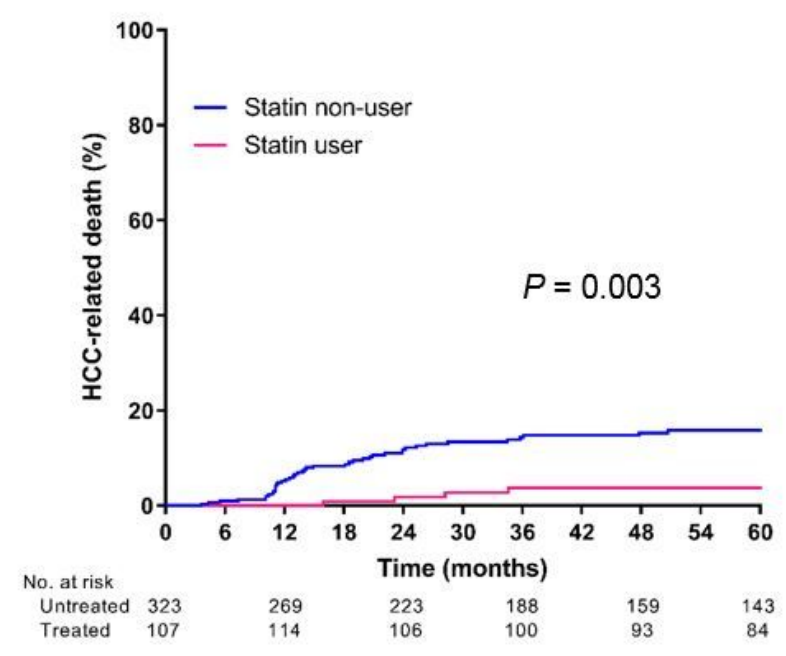

Comparison of the cumulative incidence of patient outcomes between statin user and non-user groups. a. $\mathrm{HCC}$ recurrence curves, b. overall survival curves, and $\mathrm{c}$. HCC-related death curves. The P values were calculated by Gray's test, considering death or loss to follow-up before HCC recurrence as competing events for HCC recurrence and death from causes other than HCC and loss to follow-up for HCC-related mortality. HCC, hepatocellular carcinoma 


\section{Figure 2}

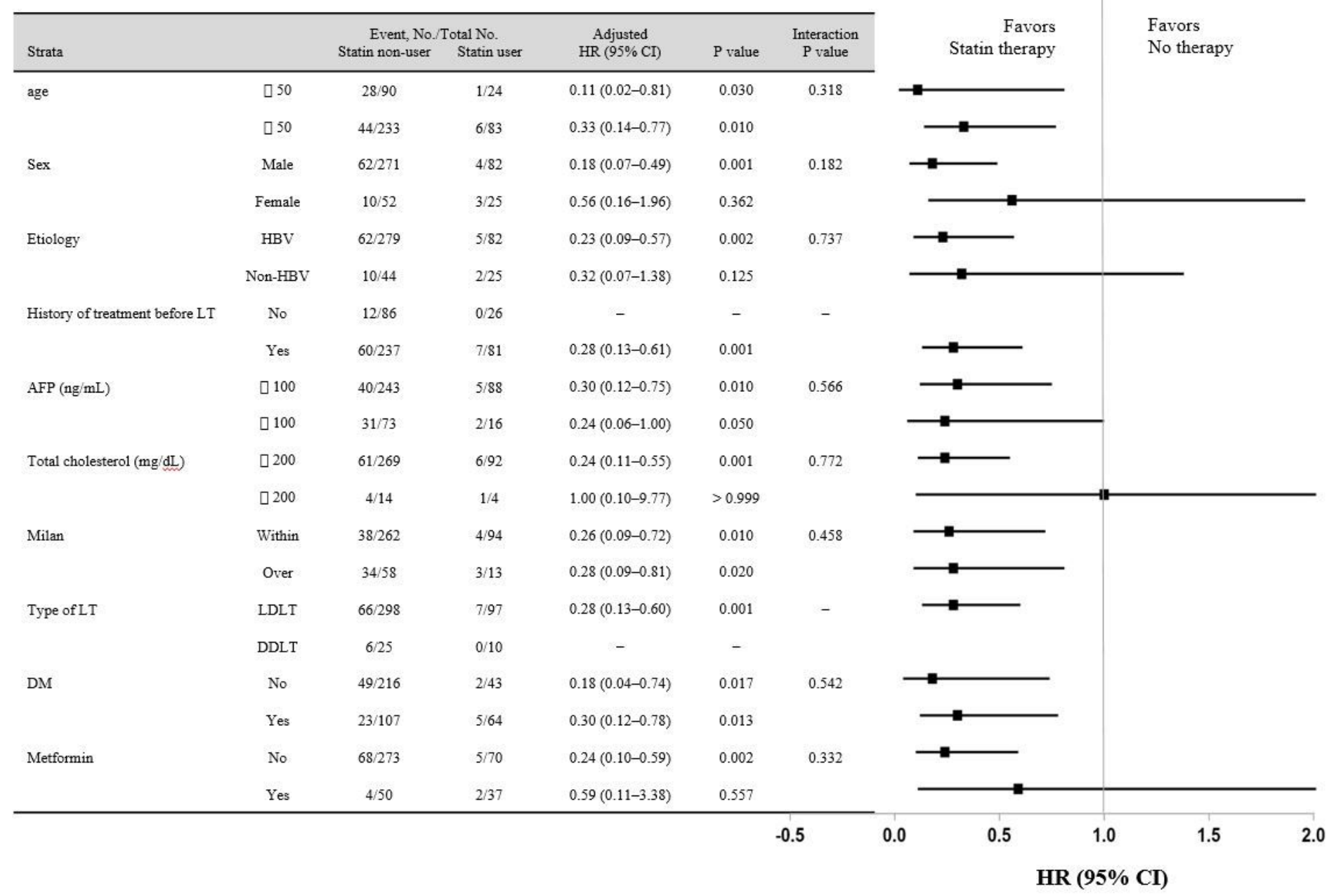

\section{Figure 2}

Multivariable-stratified analyses of the statin effect on HCC recurrence in patients who underwent LT for HCC. AFP, alpha-fetoprotein; DDLT, deceased donor liver transplantation; DM, diabetes; HCC, hepatocellular carcinoma; HR, hazard ratio; LDLT, living donor liver transplantation; LT, liver transplantation; No., number

\section{Supplementary Files}

This is a list of supplementary files associated with this preprint. Click to download.

- supplementarytable.docx 